International Journal of Applied Dental Sciences 2020; 6(4): 149-152

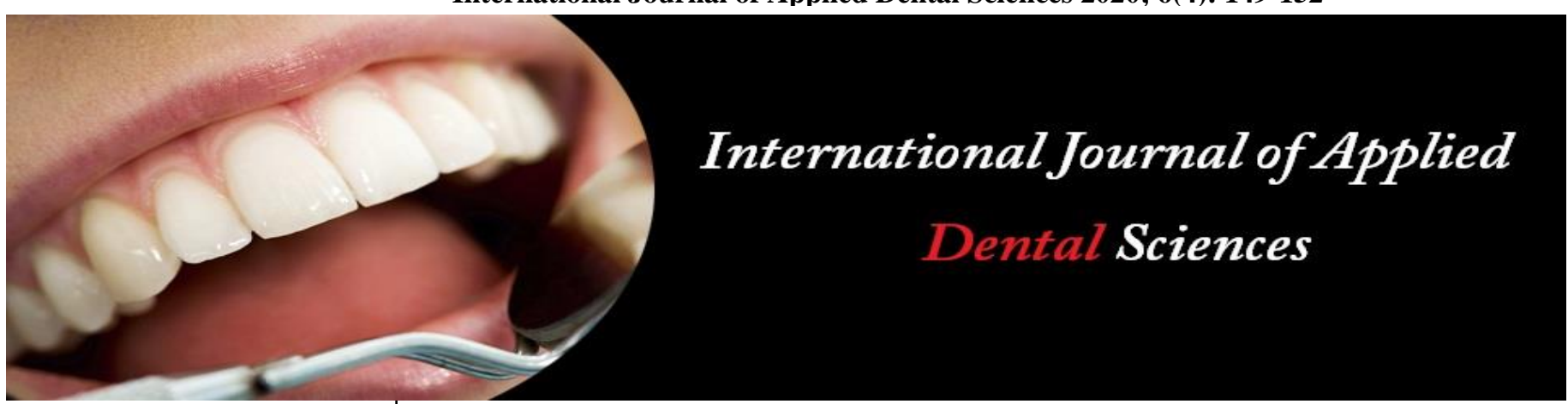

ISSN Print: 2394-7489

ISSN Online: 2394-7497

IJADS 2020; 6(4): 149-152

(C) 2020 IJADS

www.oraljournal.com

Received: 04-08-2020

Accepted: 06-09-2020

Marilyn Tereza Rodrigues

Consultant Prosthodontist,

Department of Prosthodontics;

Gem Dental Clinic, Goa, India

\section{Shreya Bukkapatnam}

Senior Lecturer, Department of Prosthodontics; Rajarajeshwari Dental College and Hospital,

Bengaluru, Karnataka, India

Babashankar Alva

Senior Lecturer; Department of Prosthodontics; Faculty of Dental Sciences, M.S Ramaiah University of Applied Sciences, Bengaluru, Karnataka, India

Corresponding Author: Marilyn Tereza Rodrigues Consultant Prosthodontist, Department of Prosthodontics Gem Dental Clinic, Goa, India

\section{Improving facial esthetics with cheek plumpers: Case reports}

\section{Marilyn Tereza Rodrigues, Shreya Bukkapatnam and Babashankar Alva}

DOI: $\underline{\text { https://doi.org/10.22271/oral.2020.v6.i4c.1058 }}$

Abstract

Facial aesthetics in complete denture has become an integral part of dental rehabilitation. Ageing leads to bone resorption and loss of soft tissue elasticity causing sunken or hollow cheeks. Conventional complete dentures give support to the circum oral musculature but do not help much with the cheek muscles. Cheek plumpers in complete dentures provide support to the cheek musculature enhancing the facial features and psychological well being of the patient. This article presents two simple, easy and effective methods of providing cheek plumpers to patients seeking for enhanced facial esthetics.

Keywords: Cheek plumper, hollow cheek plumper, sunken cheeks, facial aesthetics

\section{Introduction}

Facial aesthetics has been given a lot of importance nowadays as every individual is seeking ways and methods to improve and enhance their appearance. As Prosthodontists, we should treat the patient as a whole taking facial features into account, as the end result should merge with the orofacial structures such as the lips, cheeks, nose, eyes and facial musculature ${ }^{[1]}$.

Ageing causes loss of bone and tonicity of oro- facial musculature leading to stretching of soft tissue. When most of the dentition is lost there is massive buccal and crestal bone resorption that occurs at an increased rate. Some individuals present with a considerable amount of subcutaneous atrophy which causes the formation of concavities below the malar processes [2]. As the muscles are unsupported, they lose function and become weak, which gives rise to wrinkles and sagging, lips and cheeks. Conventional complete dentures do provide support to the circum-oral musculature but do not give enough of support to the cheek muscles. Therefore, a cheek plumper is required to enhance the facial appearance and prevent the sagging of the cheek muscles ${ }^{[3,4]}$.

A Cheek plumper or cheek lifting appliance is basically a prosthesis to enhance the support of sunken cheeks providing better esthetics ${ }^{5}$. They can be of two types: detachable and undetachable ${ }^{6}$. Both these can be used to improve facial aesthetics and therefore improve the confidence of the patient. This clinical report is directed towards enhancing the facial appearance of patients with sunken cheeks using the methods mentioned above.

\section{Case Report}

Case 1: Detachable cheek plumper with attachments.

A 65 years old male patient reported to our department, complaining of missing teeth for the past 3yrs. Extra oral examination revealed that patient had unsupported oral musculature, poor aesthetics and sunken cheeks. Intra oral examination, patient had completely edentulous maxillary and mandibular arches. Patient was very conscious about his sunken cheeks and desired a prosthesis that could restore his fullness of cheeks along with replacing his missing teeth. He was psychologically stressed due to his appearance and wanted a solution for the same. Keeping patient's esthetic demands in mind, complete dentures with detachable cheek plumper was planned. 


\section{Technique}

Coventional procedures for fabricating complete dentures were followed upto the try in appointment. During the try in, the waxed maxillary and mandibular dentures were placed and inspected for occlusion, phonetics and esthetics. At the same appointment, cheek plumpers made in wax were attached to the maxillary waxed up dentures. Two cuboidal projections were made on the cheek plumpers to fit into the cuboidal slots made on the buccal surface of the waxed denture in molar - premolar region to provide proper seating of cheek plumpers without rotation. It was then evaluated for desired fullness of patient's cheeks. A dramatic improvement was noticed in patient's appearance and patient readily accepted it. Following try in, cheek plumpers were separated from the waxed dentures and both were processed separately using heat cure acrylic resin (Dentsply Trevalon heat cure material) After de-flasking, processed dentures and plumpers were retrieved, trimmed, finished and polished(fig 1a, 1b).

A pair of precision attachments; $5 \mathrm{~mm}$ with ball attachment (fig 1c)were cast in cobalt chromium alloy. The male component was attached on the buccal surface of the dentures and female component (housing) was attached to the cheek plumper with auto polimerizing resin (fig 1d). Complete polimerization was ensured by placing both dentures and cheek plumpers in pressure pot. After insertion of the complete dentures, cheek plumpers were attached and evaluated for their position and fullness (fig 1e). They were checked for any interference with opening, closing and lateral movements of mandible. Post insertion instructions were given along with method of attaching and removal of cheek plumpers were demonstrated to the patient. The patient was recalled after 24 hours, 1 week and later every 3 months for follow up visit.

\section{Case 2: Non Detachable hollow cheek plumper}

Patient reported to the department of prosthodontics with a chief complaint of missing teeth since $3-4 y$ rs, he also mentioned that he had wrinkled and sunken cheeks. On extra oral examination it was noted that the patient had unsupported oral musculature causing wrinkled and slumped cheeks. Intra oral examination revealed fully edentulous well rounded upper and lower ridges. The patient was retired and wanted an economical fix for his functional and esthetic needs, Keeping the patients complaints and needs in mind a complete denture with a hollow non detachable cheek plumper was planned.

\section{Technique}

Conventional procedures were followed for complete denture fabrication up till the try in stage, at the try in appointment the buccal portion of the maxillary denture were built up in the premolar- molar region with wax on either side to fill the sunken cheeks of the patient (fig $2 \mathrm{a}$ ), the process was repeated till the appearance was improved and there was no interference from functional movements(fig $2 b$ ). Patient was asked to open the mouth wide and make side to side movements to check for retention after the wax was built. The height, width and length of the extension wax extension was measured and a putty index (dentsply Aquasil putty) with $2 \mathrm{~mm}$ lesser dimension was kept ready. Once the try in was completed and finalised, the complete denture was flasked. After dewaxing was completed the cavity of the complete denture was packed with the $1^{\text {st }}$ layer of heat curre acrylic resin (Dentsply Trevalon heat cure material). The putty index which was kept ready was pushed into the cheek plumper cavity (fig 2c) and another layer of acrylic was adapted over the index. A trial closure was performed using cellophane sheet. The flask was opened and checked for perforation of the index. The flask was closed and processing was completed. The complete dentures were retrived and prepared to remove the putty index from the acrylic. A small hole was made on the posterior border of the cheek plumper bulge and a 19 gauge othro wire was inserted into the putty and pulled out. The hole was then closed with cold cure acrylic resin. The denture was trimmed, finished and polished. On the day of insertion the upper complete denture was checked for extensions, retention, phonetics and appearance (fig $2 \mathrm{~d}$ ). The patient was very happy with the appearance and fit of the denture. Post insertion instructions were given and patient was called for follow up after 24 hours, 1 week and later every 3 months.

\section{Discussion}

Esthetics in complete denture should not be confined to only the selection of form and contours of teeth but should be approached with a holistic viewpoint. In the modern world complete dentures should strike a balance between the natural and artificial tissues ${ }^{[5]}$. Due to ageing and loss of teeth in the anterior and posterior region there is loss of subcutaneous buccal pad of fat which causes changes in the soft tissue contours leading to sunken or depressed appearance of cheeks [7]. Complete denture with cheek plumpers are used to enhance the facial esthetics of the patient. They can be fabricated with various types of attachments such as magnets ${ }^{[1,5]}$, push button attachments ${ }^{[6,9]}$, non detachable plumpers ${ }^{7}$ or die pin retained ${ }^{[8]}$. In the present report we have presented two methods of fabricating detachable and non detachable cheek plumpers. The hollow cheek plumper described above gives good esthetics, reduces weight of the denture, is economical and simple to fabricate, however may compromise retention and stability ${ }^{[9]}$. The advantages of using a cobalt- chromium ball retained attachment are the ease of insertion and removal, improved retention and corrosion resistance ${ }^{[10]}$, but is expensive and involves time consuming proedures. Hence depending on the patient expectation, financial status and clinicians judgement an appropriate method to fabricate cheek plumpers can be used effectively to improve facial esthetics of aged patients.

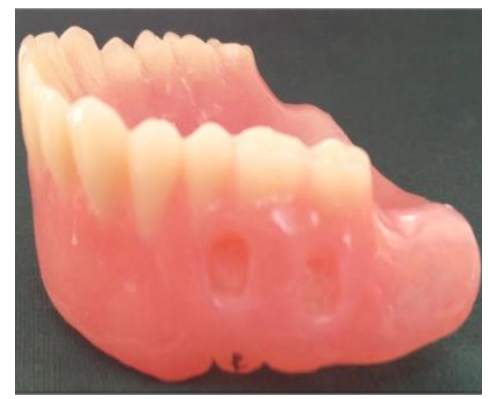

Fig 1a: Processed denture with cuboidal slots for orientation

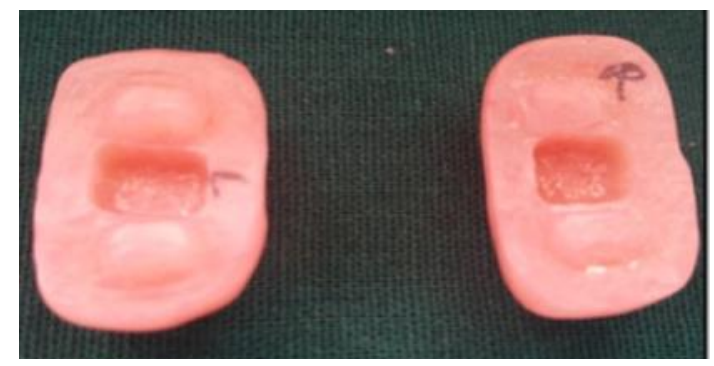

Fig 1b: Processed cheek plumpers with male component of cuboidal 


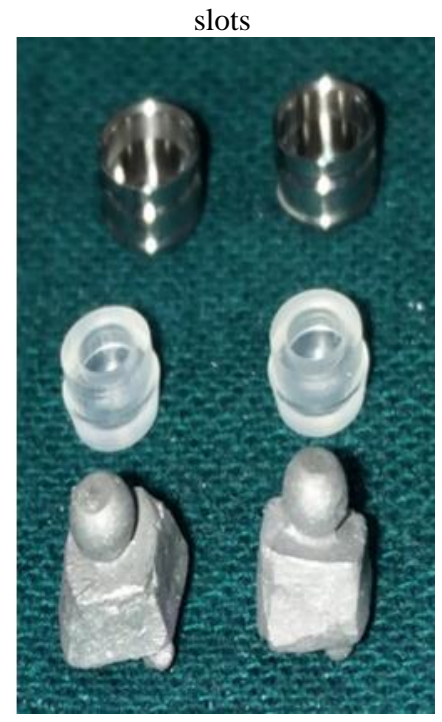

Fig 1c: ball attachments with housing

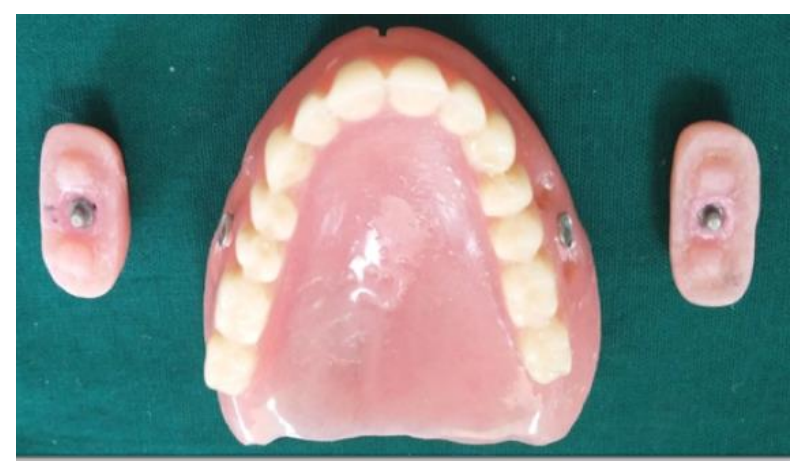

Fig 1d: attachment of male and female components of the cheek plumper

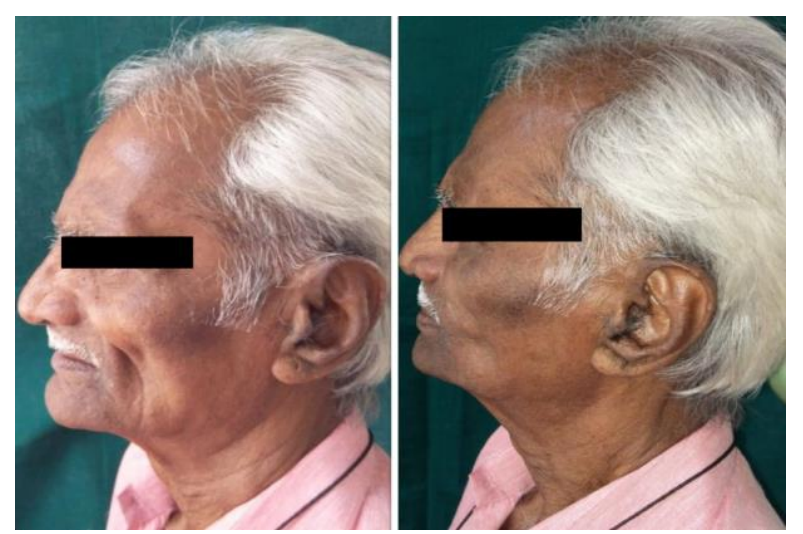

Fig 1e: lateral view showing before and after insertion of cheek plumpers

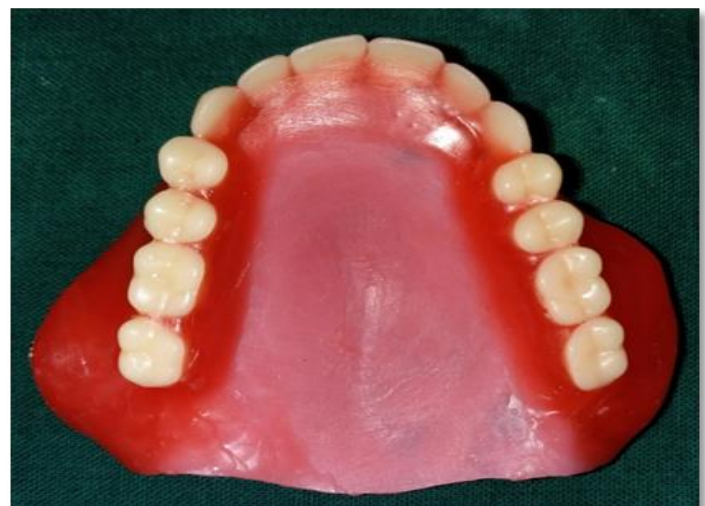

Fig 2a: Waxed denture with cheek plumper extention

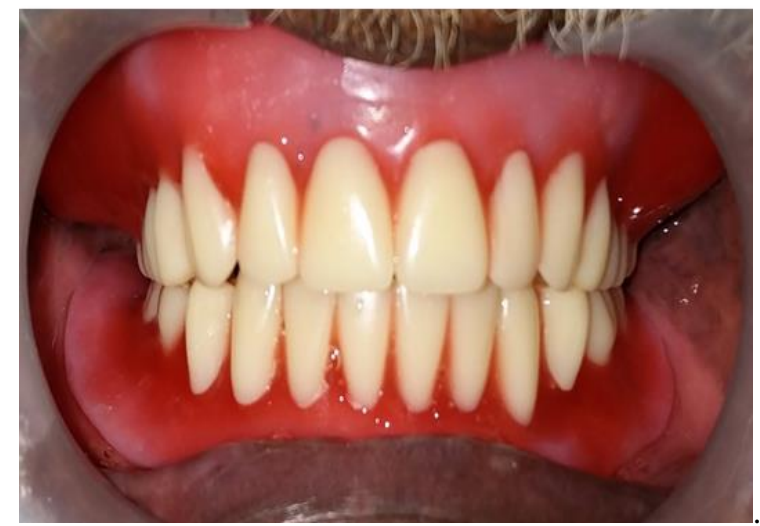

Fig 2b: try in

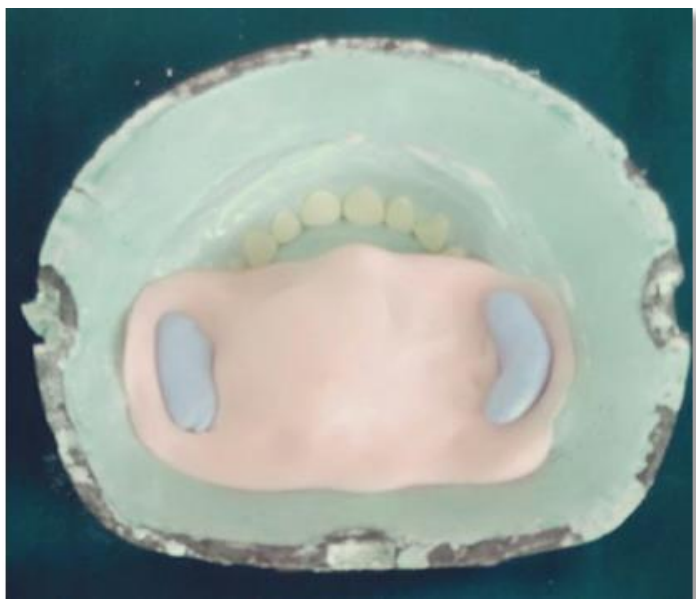

Fig 2c: packing along with putty index to make the plumper hollow

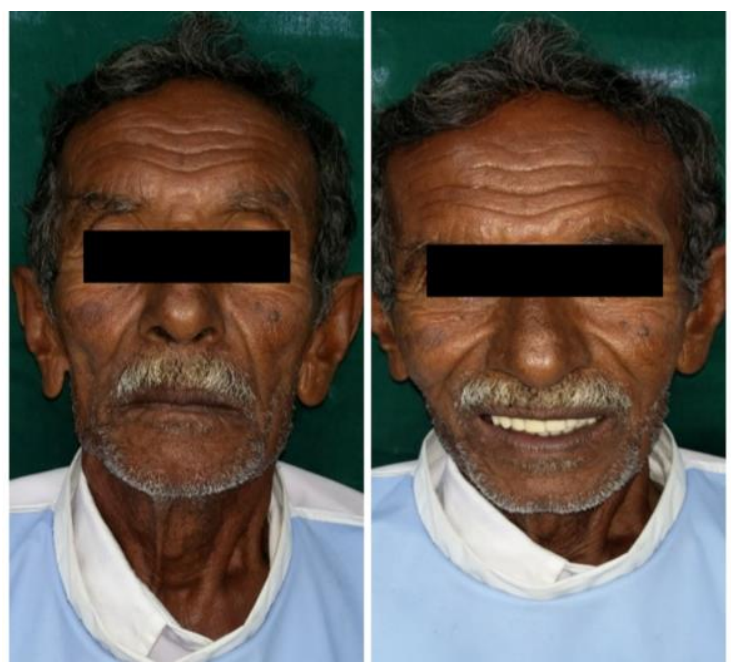

Fig 2d: before and after denture insertion

\section{Conclusion}

This article describes two simple, easy and effective methods for the fabrication of cheek plumpers for patients who desire facial esthetics with complete dentures. Cheek plumpers not only improves the esthetics but also boosts the confidence and improves the psychological well being of the patient.

\section{References}

1. Saoji S, Agrawal S, Bhoyar A, Parlani S. Restoring esthetics with magnet retained cheek plumpers. Indian Journal of Comprehensive Dental Care (IJCDC) 2015;5(2).

2. Bains JW, Elia JP. The role of facial skeletal augmentation and dental restoration in facial 
rejuvenation. Aesthetic plastic surgery 1994;18(3):243-6.

3. Zwetchkenbaum SR, Shay K. Prosthodontic considerations for the older patient. Dental clinics of North America 1997;41(4):817-45.

4. Fernandes A, Correia M, Pinto N. Prosthesis for cheek support-a case report. J Indian Prosthodont Soc. 2002;2(4):19-20.

5. Deogade SC. Magnet retained cheek plumper in complete denture esthetics: a case report. Journal of Dentistry (Tehran, Iran) 2014;11(1):100.

6. Aggarwal P, Gupta MR, Pawah S, Singh A. An innovative technique to improve complete denture aesthetics using cheek plumper appliance: a case report. Int J Oral Health Med Res 2016;3:51-4.

7. Mor D, Sarapur S, Adeshra K, Pachore N, Rami D. Management of Hollow Cheeks with Undetachable Hollow Cheek plumper: A Case Report. Journal of Advanced Health Sciences and Research. 2020;1(1):61.

8. Pudi S, Kota S, Ch KK, Kaladi SR, Gade RR. An Innovative Technique Using a Stainless Steel Double Die Pin Retained Cheek Plumper in Complete Denture Esthetics: A Case Report. Cureus 2019;11(11).

9. Sandebiksham P, Kumar CR, Rao DC, Kumar GS. Esthetics redefined by cheek props-A case report. Annals of Prosthodontics \& Restorative Dentistry 2017;3(2):737.

10. Keni NN, Aras MA, Chitre V. Customised attachments retained cheek plumper prosthesis: a case report. The Journal of Indian Prosthodontic Society. 2012;12(3):198200. 